\title{
PEMANFAATAN E-LEARNING BERBASIS LCMS MOODLE DALAM PENINGKATAN EFISIENSI DAN EFEKTIVITAS SERTA KUALITAS MEDIA PEMBELAJARAN SISWA DI MAN SAKATIGA
}

\author{
Annisa Turrahma ${ }^{1}$, Erma Novita Satyariza ${ }^{2}$, Ali Ibrahim ${ }^{3}$ \\ 1,2,3 Sistem Informasi/Sistem Informasi Reguler, Universitas Sriwijaya, Palembang, Indonesia \\ e-mail:annisaturrahma95@gmail.com¹, ermanovitasatyariza@gmail.com², \\ aliibrahimbengkulu21@gmail.com ${ }^{3}$
}

\begin{abstract}
Abstrak
Seiring dengan perkembangan teknologi, proses belajar mengajar tidak hanya mengandalkan tatap muka secara langsung yang diselenggarakan didalam kelas, namun juga mengandalkan media lain, seperti media ICT yang dapat digunakan sebagai salah satu bentuk penyebaran materi pembelajaran. $E$ Learning sangat potensial untuk dijadikan sebagai salah satu media interakti yang dapat membantu meningkatkan kualitas pembelajaran karena siswa dapat mengakses materi pembelajaran selain itu juga kesempatan untuk berinteraksi dengan pengajar akan terbuka lebih luas. Selain itu E-Learning juga berfungsi sebagai forum diskusi antara pengajar dan siswa, dan juga dapat digunakan sebagai kuis online, sehingga semua kegiatan proses pembelajaran menjadi sangat efektif dan efisien.
\end{abstract}

Kata kunci:E-Learning, kualitas pembelajaran, efektif, efisien

\begin{abstract}
Along with the development of technology, teaching and learning process not only rely on face-to-face directly held in the classroom, but also rely on other media, such as ICT media that can be used as one form of dissemination of learning materials. E-Learning is potential to serve as one of the interactial media that can help improve the quality of learning because students can access the learning materials as well as the opportunity to interact with teachers will open more widely. Besides it e-learning also serves as a discussion forum between teachers and students, and can also be used as an online quiz, so all the process activities learning becomes very effective and efficient.
\end{abstract}

Keywords: E-Learning, learning quality, effective, efficient

\section{PENDAHULUAN}

Di era ini, Ilmu dan teknologi informasi yang semakin berkembang pesat tentunya akan menimbulkan dampak yang baik, pesatnya perkembangan teknologi ini berdampak pada perubahan sosial budaya, seperti perubahan di dunia pendidikan salah satunya adalah pemanfaatan media E-Learning sebagai penunjang kualitas pendidikan, E-Learning merupakan proses pembelajaran melalui media elektronik terutama internet. Saat ini, E-Learning menjadi media pembelajaran yang digunakan selain tatap muka di kelas. Hal ini disebabkan karena E-Learning memungkinkan peserta didik untuk dapat belajar maupun mendapatkan ilmu pengetahuan kapan pun dan dimana pun dia berada. E-Learning juga menjadi alternatif bagi peserta didik yang mengalami kejenuhan belajar dalam tatap muka di kelas.

Menurut (Pelikan, 1992) suatu pembelajaran dapat berjalan dengan baik dan dapat mencapai tujuannya apabila terdapat tiga aspek dalam proses belajar mengajar yang komposisinya berjalan dengan serasi yaitu komunikasi antar 
pengajar dengan siswa, komunikasi antar siswa dengan sumber belajar, dan komunukasi antar siswa.

Hal yang seharusnya selalu dijaga dalam sistem pembelajaran yang bersifat tatap muka di dalam kelas adalah adanya kehadiran pendidik dan peserta didik secara synchronous (komunikasi dilakukan di tempat dan waktu yang yang telah ditentukan). Apabila hal ini tidak terjaga secara intens, maka pembelajaran yang bersifat tatap muka akan terganggu. Hal ini menjadikan pembelajaran tatap muka di dalam kelas kurang praktis bagi beberapa orang, karena tidak semua orang dapat melakukan hal tersebut secaraintens (berhubungan dengan masalah pekerjaan, kesehatan dan hal-hal lain yang mendesak).

Manfaat yang bisa didapat dari pemanfaatan E-Learning adalah adanya fasilitas untuk e-moderating dimana pengajar dapat melakukan kegiatan pembelajaran tanpa terkendala oleh jarak, pengajar dan siswa juga dapat mengunakan bahan ajar melalui internet, siswa dapat me-review materi pembelajaran secara online, jika siswa memerlukan bahan tambahan untuk belajar maka siswa dapat mengakses internet, perubahan peran siswa dan pengajar menjadi lebih aktif dan pembelajaran relatif lebih efisien dan efektif.

MAN Sakatiga merupakan satu dari banyak sekolah menengah atas yang ingin memanfaatkan teknologi e-learning untuk meningkatkan pelayanan pendidikannya.Beberapa sekolah menengah atas yang lain telah memanfaatkan e-learning. Oleh karenaitu MAN Sakatiga akan memilih sistem elearning yang sesuai untuk di implementasikan. Oleh sebab itu penulis akan melakukan penelitian untuk membantu MAN Sakatiga dalam mengembangkan sistem e-learning disana.

\section{KAJIAN PUSTAKA}

$\mathrm{Di}$ dunia pendidikan dan pelatihan sekarang, banyak sekali praktik yang disebut E-Learning. Sampai saat ini pemakaian kata E-Learning seringdigunakan untuk menyatakan semua kegiatan pendidikan yang menggunakan media komputer dan Internet. Banyak pula terminologi lain yang mempunyai arti hampir sama dengan E-Learning, diantaranya : Web-based training, online learning, computer-based training/ learning, distance learning, computer-aided instruction, dan lainnya. Terminologi ELearning sendiri dapat mengacu pada semua kegiatan pelatihan yang menggunakan media elektronik atau teknologi informasi (Effendi dan Zhuang, 2005).

Karena ada bermacam penggunaan ELearning saat ini, maka ada pembagian atau perbedaan E-Learning. Pada dasarnya, E-Learning mempunyai dua tipe, adalah synchronous dan asynchronous (Hadiana dan Djaelani, 2003).

Menurut (Surendro, 2005)E-Learning merupakan usaha membangun transformasi proses belajar-mengajar yang ada di sekolah ke dalam bentuk digital yang dijembatani oleh internet. E-Learning diartikan sebagai bentuk teknologi informasi yang diterapkan dalam bidang pendidikan dalam bentuk kelas maya. Atinya siswa dan pengajar tidak harus melakukan pertemuan secara langsung, melainkan mereka dapat berinteraksi secara tidak langsung melalui komputer masing-masing dalam melakukan proses belajar dan mengajar.

Sejalan dengan penelitian ini, penelitian terdahulu yang berjudul APLIKASI E-LEARNING BERBASIS WEB DENGAN MENGGUNAKAN ATUTOR juga membahas hal yang sama mengenai peningkatan kualitas pendidikan yang mana menghasilkan kesimpulan adanya aplikasi E-Learning berbasis web yang interaktif 
dengan fasilitas komunikasi blog membuat instruktur dan peserta didik dapat berkomunikasi membahas materi di dalam pembelajaran maupun materi di luar pembelajaran melalui komentar yang diberikan.

Disamping itu, dengan adanya media pengiriman tugas oleh peserta didik berdasarkan kelompok secara langsung membuat proses pembelajaran di dalam $E$ Learning menjadi efektif dan efisien. Dengan demikian fasilitas komunikasi serta media pengiriman tugas sangat dibutuhkan dalam suatu E-Learning agar proses pembelajaran dapat maksimal.

\section{METODOLOGI PENELITIAN}

Perangkat lunak Learning Content Management System merupakan sistem yang memanfaatkan internet untuk menyampaikan materi pembelajaran yang memenuhi kebutuhan individual siswa. Perangkat lunak ini akan digunakan oleh tiga kategori pengguna, yaitu administrator, pengajar, dan siswa. Seorang pengajar yang telah terdaftar dapat memasukkan materi pembelajaran yang akan disampaikan; atau memilih materi pembelajaran yang sudahpernah disampaikan kepada siswa untuk dimodifikasi. Materi pembelajaran yang dimasukkan oleh pengajar pada awalnya hanya berdasarkan prediksi pengajar terhadap kebutuhan siswa. Pengajar yang telah terdaftar juga dapat memasukkan soal yang akan diujikan atau memilih soal yang sudah pernah diujikan kepada siswa untuk dimodifikasi. Selanjutnya, data berupa materi pembelajaran dan soal ujian tersebut akan diolah oleh perangkat lunak menjadi keluaran yang diperlukan bagi siswa yaitu materi pembelajaran yang tepersonalisasi sesuai dengan level dan preferensi pembelajaran siswa.

Komponen-komponen LCMS terdiri dari (Kridanto Surendro):

1. Learning Object Repository

Learning object repository adalah database di mana materi pembelajaran disimpan dan dikelola.

\section{Automated Authoring Application}

Aplikasi ini digunakan untuk membuat objek pembelajaran yang dapat digunakan kembali (reusable) yang dapat diakses dari repository. Aplikasi ini memungkinkan author menggunakan objek pembelajaran yang sudah ada di repository, kemudian membuat objek pembelajaran baru serta dapat mengkombinasi antara kedua objek pembelajaran tersebut.

\section{Dynamic Delivery Interface \\ Untuk memberikan}

objek pembelajaran yang sesuai dengan profil siswa, hasil evaluasi, dan informasi siswa lainnya, dibutuhkan sebuah dynamic delivery interface. Komponen inijuga menyediakan user tracking, link ke sumber informasi yang berhubungan, dan juga mendukung tipe penilaian yang beragam dengan umpan balik dari siswa.

3. Administrative Application

Aplikasi bertujuan untuk mengelola hasil belajar siswa dan mengamati dan melaporkan kemajuan siswa, serta menyediakan fungsi administratif dasar lainnya.

\section{HASIL DAN PEMBAHASAN}

Hasil yang dicapai didalam pemanfaatan E-Learning:

Terjadi interaksi antara pengajar dan siswa didalam kelas Online, siswa yang ketinggalan pelajaran dapat mengakses materi yang telah di sediakan oleh pengajar, dan materi dapat diakses secara bersama-sama tanpa ada limit waktu. Fasilitas yang diberikan LCMS Moodle dapat digunakan sebagai wadah interaksi seperti:

a. Fitur Message yaitu membuat siswa dan pengajar dapat melakukan interaksi sesuai dengan topik bahasan. Antar siswa juga dapat melakukan pesan singkat dengan mengklik salah satu user yang terdapat di kelas online masingmasing, bahkan dengan pengajar itu sendiri. Notifikasi pesan akan muncul sehingga pengajar dapat membuka pesan tersebut. 
b. Forum diskusi yaitu merupakan fasilitas dari fitur Moodle yang digunakan sebagai wadah komunikasi antara siswa maupun pengajar mengenai materi kelas yang berlangsung. Berbeda denga fitur pesan pada forum diskusi pengajar dapat melakukan penilaian subjektif maupun objektif terhadap tanggapan atau opini dari siswa. Selain itu fasilitas lainnya adalah pemanfaatan dokumen dengan berbagai format. Beberapa format yang telat di dukung oleh LCMS Moodle yaitu format dokumen baik portable maupun editable seperti PDF, DOC, XLS, ODT, dan sebagainya. Selain itu apabila pengajar mempunyai akun pada penyimpanan berbasis Cloud seperti Box, Google Drive, Dropbox dan sebagainya. Akun cloud tersebut dapat ditautkan ke LCMS Moodle.

c. Pengumpulan Tugas, fitur ini dapat digunakan dengan memanfaatkan fasilitas unggah. Selain dapat mengunggah data, fitur ini juga dapat melakukan penerapan batas waktu pengumpulan data dan nilai.

d. Kuis Online Fasilitas ini ditujukan agar pengajar dapat melakukan evaluasi mata pelajaran secara objektif, seperti pelaksanaan kegiatan Kuis PreTest. Kegiatan ini bertujuan untuk mendapatkan gambaran tentang mata pelajaran terdahulu yang berhubungan dengan mata pelajaran yang akan diajarkan.

e. Pemanfaatan E-Learning dilakukan secara efektif dan efisien sesuai dengan materi pelajaran. Jadwal, kumpulan materi serta materi tambahan dapat disampaikan kepada siswa secara keseluruhan, dibandingkan pembelajaran konvensional, pengajar bersifat sentralistik dan terpola pada jadwal menyebabkan materi yang disampaikan terkesan cepat dan cenderung tidak tersampaikan. Pemanfaatan moodle sebagai LMS dilaksanakan secara efektif dan efisien sesuai dengan jadwal kegiatan pembelajaran. Sehingga peserta dapat mengikuti jadwal kegiatan dan aktivitas pembelajaran sesuai dengan waktunya maupun tambahan informasi yang sesuai dengan materi pelajaran yang diajarkan.

f. Pemanfaatan e-learning dapat meningkatkan kualitas Pengajar di MAN Sakatiga. Pengajar dapat meningkatkan kemampuannya dan mengekplorasi pengetahuan baru dan dapat diajarkan kepada siswa dengan menggunakan pendekatan teknologi informasi dan komunikasi. Kegiatan belajar tercapai sesuai dengan rancangan kegiatan belajar mengajar tanpa adanya batasan ruang dan waktu.

\section{PEMBAHASAN}

Pemanfaatan E-Learning sebagai media pembelajaran dirasakan siswa pada saat kegiatan pembelajaran. Kuesioner diambil secara online dengan memanfaatkan aplikasi LCMS Moodle, interaksi siswa dengan pengajar selalu berjalan dengan baik, hal ini dapat dilihat siswa selalu tepat waktu saat dikelas dan dalam pengumpulan tugas siswa sering mengerjakan dan mereka membentuk kelompok diskusi sendiri untuk membahas materi pelajaran. Melalui penerapan ELearning yang digunakan sebagai media pembelajaran, siswa berpendapat bahwa ELearning adalah sesuatu yang baru sehingga siswa selalu aktif didalam proses pembelajaran di E-Learning. Kreativitas muncul pada saat siswa didalam proses kegiatan belajar mengajar.

Kendala yang dihadapi siswa pada saat mengumpulkan tugas terjadi saat fasilitas yang digunakan tidak memadai seperti perangkat komputer dan internet. Siswa selalu menggunakan smartphone, dimana hal ini tidak semua bisa dilakukan seperti halnya perangkat komputer, karena perangkat smartphone mempunyai keterbatasan seperti fasilitas compress, aplikasi perkantoran, pembuat bagan flowchart yang dapat mendukung materi pelajaran selain jaringan internet itu sendiri.

B. Lena Nuryanti (2003 dan 2004) menemukan bahwa model pembelajaran elearning melalui homepage sebagai media 
pembelajaran sehingga dapat meningkatkan minat dan kreativitas siswa. Ada hubungan yang positif antara media pembelajaran homepage dengan dengan kreativitas siswa, dan ada hubugan juga bahwa melalui homepage sebagai media pembelajaran mempunyai hubungan yang erat dengan minat belajar siswa. Pada kegiatan pembelajaran komunikasi terjalin antara Pengajar dan siswa melalui pemanfaatan E-Learning. Informasi yang disajikan melalui E-Learning dapat dengan mudah diperoleh siswa kapan pun sehingga didalam mengerjakan tugas tidak mengalami kendala.

Pemanfaatan pesan singkat pada ELearning digunakan siswa didalam berinteraksi dengan dosen tentang materi pada mata kuliah tersebut. Kendala siswa di dalam menggunakan E-Learning karena siswa masih menganggap belum adanya kebutuhan yang mendesak pada saat penerapan E-Learning. Pembelajaran konvensional masih menjadi kebiasaan yang selalu dilakukan sehingga pengajar perlu mengingatkan bahwa E-Learning merupakan bagian dari proses pembelajaran pada mata pelajaran tersebut.

Menurut Nedelko (2008) menyatakan bahwa format penerapan E-Learning salah satunya blended or mixed mode ELearning, yaitu sebagai proses pembelajaran dilakukan secara tatap muka dan sebagian lagi dilakukan secara online. Berdasarkan teori tersebut menjelaskan bahwa pemanfaatan E-Learning yang digunakan sebagai media pembelajaran melakukan kombinasi antara pembelajaran konvensional dan pembelajaran dengan menerapkan E-Learning.

Sejalan dengan temuan Nurina Kurniasari Rahmawati, Teguh Wibowo, Nila Kurniasih (2012) melakukan penelitian model pembelajaran E-Learning pada proses pembelajaran Matematika siswa kelas VIII SMPN se-Kecamatan Banyuurip ditinjau dari motivasi belajar siswa memberikan hasil belajar matematika yang lebih baik dari model pembelajaran konvensional.

\section{SIMPULAN}

Simpulan yang didapat dari penelitian ini adalah:

1. Aplikasi LCMS berguna untuk memudahkan pengajar dalam mengelola materi pembelajaran serta soal ujian yang akan diberikan kepada siswa.

2. Penyampaian materi pembelajaran yang baik pada suatu kelas maya tidaklah mudah. Dengan aplikasi LCMS, penyampaian materi pembelajaran dapat dilakukan dengan lebih baik sesuai dengan kebutuhan siswa. LCMS memberikan materi pembelajaran yang tepersonalisasi kepada siswa melalui 2 cara yaitu: dengan pemantauan interaksi siswa dengan materi pembelajaran yaitu dengan menyimpan tingkah laku siswa dalam pengaksesan materi pembelajaran sebelumnya (preferensi pembelajaran) ke basis data. Penyampaian materi pembelajaran disesuaikan dengan level siswa saat ini sehingga diperlukan proses evaluasi untuk mengukur tingkat kemajuan siswa.

3. Proses evaluasi pada aplikasi LCMS berguna bagi pengajar untuk mengetahui tingkat penguasaan siswa terhadap suatu materi pembelajaran sehingga dapat membantu pengajar untuk menganalisis kejelasan, relevansi, dankeefektifan dari materi pembelajaran tersebut.

\section{REFERENSI}

[1] Arianti, Y. M., \& Yogisa, K. (2012). Aplikasi E-Learning Berbasis Web Dengan Menggunakan Atutor. UG Jurnal, Vol.6, 14-17.

[2] Aribowo, A. S. (2010, Mei 22). ELearning Cerdas Dengan Personalisasi Menggunakan Teknik Data Mining Dan Decision Support System. Seminar Nasional Informasi 2010 (semnasIF2010) , 80-86. 
[3] Arjana, A. (2010). Pembuatan Aplikasi Pembelajaran Online (E-Learning) Untuk Sekolah Menengah Dan Sederajat.

[4] Cabezas, M. F. (2017). From the Teaching-Based Model to the LearningBased Model: A Comparative Study. 7th International Conference on Intercultural Education "Education, Health and ICT for a Transcultural World", EDUHEM 2016, 15-17 June 2016, Almeria, Spain , 678-684.

[5] Hanum, N. S. (2013). Keefektifan ELearning Sebagai Media Pembelajaran (Studi Evaluasi Model Pembelajaran ELearning SMK Telkom Sandhy Putra Purwokerto). Jurnal Pendidikan Vokasi , 90-102.

[6] Harahap, S. H. (2015). Pemanfaatan ELearning Berbasis LCMS Moodle Sebagai Media Pembelajaran Untuk Mata Kuliah Sistem Informasi Akuntansi. Jurnal Riset Akuntansi Dan Bisnis, 86-99.

[7] Hidayati, N. (2010). Sistem E-Learning Untuk Meningkatkan Proses Belajar Mengajar : Studi Kasus Pada SMK Negeri 10 Bandar Lampung. Jurnal TELEMATIKA MKOM, Vol.2, 153-170.

[8] Kennerwell, S. (2001). Using Affordances and Constraints to Evaluate the Use of Information and Communications Technology in Teaching and Learning. Journal of Information Technology for Teacher Education, Vol. 10, Nos 1\&2, 2001 , 101-116.

[9] Klement, M., Dostal, J., \& Maresova, H. (2013). Elements Of Electronic Teaching Material With Respect To Students Cognitive Learning Styles. International Conference On Education And Education Psychology 2013 (ICEEPSY 2013) , 437-446.

[10] Prasetyo, B. H., \& Anubhakti, D. (2011). Kajian Penerimaan Sistem ELearning Dengan Menggunakan Pendekatan UTAUT Study Kasus Fakultas Teknologi Informasi Universitas Budi Luhur. BIT, Vol.8, 4547.
[11] Richards, C. (2005). The Design Of Effective ICT-Support Learning Activities : Exemplary Models, Changing Requirements, And New Possibilities. Language Learning and Technology , 60-79.

[12] Surendro, K. (2005). Pengembangan Learning Content Management System yang Mendukung Peningkatan Efektifitas Proses Belajar Jarak Jauh. Vol.5, 45-52.

[13] Susanti, E., \& Sholeh, M. (2008). Rancang Bangun Aplikasi E-Elearning. Jurnal Teknologi, Vol.1, 53-57.

[14] Yazdi, M. (2012). E-Learning Sebagai Media Pembelajaran Interaktif Berbasis Teknologi Informasi. Jurnal IImiah Foristek, Vol. 2, 143-152. 